\title{
Extrapyramidal Side Effects of Antipsychotic Treatment: Scope of Problem and Impact on Outcome
}

\author{
Rajiv Tandon, MD ${ }^{1,2}$ and Michael D. Jibson, MD, PhD $^{1}$
}

Previously, clinicians worked with antipsychotic drugs (conventional or typical) that almost
invariably caused extrapyramidal symptoms (EPS) at clinically effective doses. This led to
the false impression that all antipsychotics were the same, and that EPS were an unavoid-
able consequence of effective antipsychotic therapy. EPS adversely impact several aspects
of antipsychotic efficacy and tolerability, thereby worsening outcome of afflicted individuals.
EPS reduce beneficial effects of antipsychotic treatment on the negative, cognitive, and mood
symptom domains, while increasing the risk of tardive dyskinesia and reducing compliance. By
definition, the newer generation of "atypical" antipsychotic agents are significantly better than
conventional agents with regard to EPS (i.e., they are clinically effective at doses at which they
do not cause EPS). Pharmacologically, this difference is expressed in the greater degree of sep-
aration between respective dose response curves for antipsychotic and EPS effects observed
for "atypical" in contrast to conventional agents. Clinically, this EPS advantage of atypical
antipsychotics translates into several important benefits, including better negative symptom
efficacy, less dysphoria, less impaired cognition, a lower risk of TD, and better overall outcome.

KEY WORDS: akathisia; akinesia; dyskinesia; extrapyramidal symptoms; parkinsonism; antipsychotic; neuroleptic; treatment.

\section{INTRODUCTION}

The past decade has witnessed an unprecedented development of a new generation of so-called "atypical" antipsychotic medications. Following the introduction of clozapine in the United States in 1990, risperidone, olanzapine, quetiapine, and ziprasidone have become available for general clinical practice. As with their neuroleptic predecessors, these medications are effective in reducing the delusional thinking, hallucinatory experiences, and thought disorganization that are the hallmarks of psychosis. Compared to older medications, however, these agents are associated with a much lower risk of extrapyramidal side effects (EPS), which were a bane of the older generation of conventional antipsychotics. In contrast to the

\footnotetext{
${ }^{1}$ University of Michigan, Ann Arbor, Michigan.

${ }^{2}$ To whom correspondence should be addressed at University of Michigan Hospitals, 1500 E. Medical Center Drive, Ann Arbor, Michigan 48109-0120; e-mail: rtandon@umich.edu.
}

older conventional antipsychotics, the newer atypical antipsychotics are better able to separate the therapeutic antipsychotic effect from EPS (1-6).

\section{EXTRAPYRAMIDAL SYNDROMES AND THEIR CLINICAL IMPLICATIONS}

Several extrapyramidal syndromes are associated with antipsychotic treatment. These include dystonic reactions, drug-induced parkinsonism, akathisia, akinesia, and dyskinesia. Each of these syndromes can occur acutely or late ("tardive") in the course of antipsychotic treatment and is associated with a variety of mental and other consequences. These consequences of the various syndromes are briefly reviewed.

\section{Dystonia and Drug-Induced Parkinsonism}

Acute dystonic reactions are common during neuroleptic treatment, particularly with initial doses 
of the medication; such reactions are painful and frightening and patients are predictably resistant to continuing medication following such an event. Dystonic reactions can also occur later in treatment, and this too can result in poor patient compliance because they are one of the most frightening aspects of antipsychotic therapy. Among patients who continue to take the medication, parkinsonian side effects (tremor, bradykinesia, and rigidity) impair social and occupation function, adding to the likelihood of deterioration in these areas.

Although the motor symptoms of EPS are well recognized, mental manifestations are not. Mental aspects of parkinsonism include emotional withdrawal, anhedonia, and restricted affect in the emotional domain; apathy, social withdrawal, diminished social drive and initiative in the social realm; and impaired concentration and sluggish thought processes in the cognitive domain (7). Mental aspects of EPS, along with subjective akathisia, are one of the main reasons for negative attitudes of patients and caregivers toward antipsychotics.

\section{Akathisia and Noncompliance}

Akathisia is common, often goes unrecognized by patients and physicians, and is associated with premature treatment termination because it is one of the most distressing side effects associated with antipsychotic treatment. Psychological akathisia is an uncomfortable feeling of restlessness and uneasiness. The occurrence of akathisia in the course of antipsychotic treatment has been related to exacerbation of psychotic symptoms (8) and increased suicidality (9). Akathisia is associated with extreme subjective distress, and its occurrence in the course of antipsychotic treatment results in high rates of noncompliance (10, 11). Medication noncompliance, in turn, is associated with a threefold increase in the risk of relapse $(12,13)$.

\section{Akinesia and Negative Symptoms}

Bradykinesia/akinesia is a drug-induced extrapyramidal syndrome characterized by reduced facial expression, decreased spontaneity, apathy, loss of expressive gestures, and flattening of vocal inflection; notably, these are also among the negative symptoms of schizophrenic illness. It should be noted that negative symptoms in schizophrenic patients may arise from a variety of causes, some inherent to the illness (primary symptoms), and some secondary to treat-

\section{Components of Negative Symptoms}

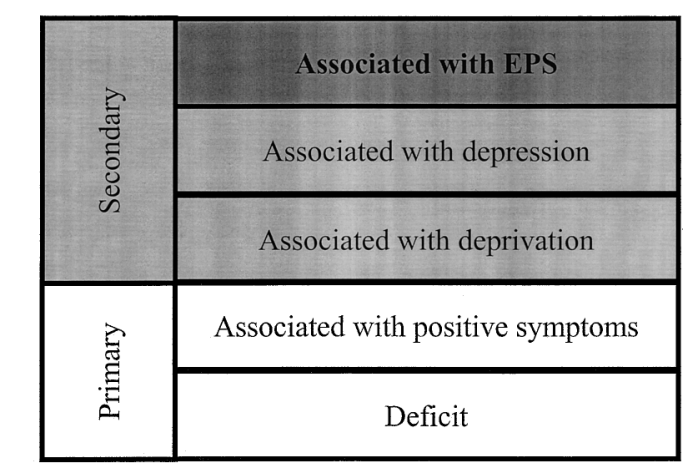

Fig. 1. Negative symptoms in schizophrenic patients may arise from various causes (7). These symptoms can be improved or worsened by treatment; antipsychotic agents improve the component of negative symptoms associated with positive symptoms, but the agents also can worsen negative symptoms associated with EPS.

ment or other psychosocial factors (Fig. 1) $(14,15)$. Distinguishing between different causes of negative symptoms is useful from a pathophysiological and management standpoint. It should be emphasized, however, that all components of negative symptoms have an adverse impact on outcome. Negative symptoms associated with EPS are disabling just as deficit or primary enduring negative symptoms are (14).

Antipsychotics reduce negative symptoms associated with positive symptoms, while sometimes adding negative symptoms related to EPS. This contribution of "secondary" negative symptoms may offset the benefits of these medications in treating negative symptoms associated with psychotic symptoms (16, 17). Because EPS may partially offset gains in negative symptoms associated with resolution of active psychosis, the newer atypical antipsychotics (because they are less likely to cause EPS) have generally been found to be more effective than conventional agents in ameliorating negative symptoms (17-19).

\section{EPS and Cognitive Impairment}

In addition to their motor symptoms, neuroleptics have been associated with cognitive dysfunction, attributable directly to EPS, to their inherent anticholinergic properties, and to the adjunctive use of other anticholinergic agents $(20,21)$. Cognitive impairment has long been described as a feature of schizophrenic illness, independent of positive or 
negative symptoms. Conventional neuroleptics have only minor effects on most aspects of cognition in schizophrenia $(22,23)$. There is some beneficial effect of typical neuroleptic treatment on measures of attention and distractibility (15). On the other hand, neuroleptic blockade of mesocortical dopamine transmission adversely impacts several aspects of cognitive function and results in bradyphrenia, characterized by slowed mentation and decreased cognitive ability. Anticholinergic activity (either intrinsic to the antipsychotic agent or due to the addition of an anticholinergic agent to treat parkinsonian side effects) adversely affects memory, learning, and other cognitive functions $(21,24,25)$. Since atypical agents are less likely than conventional neuroleptics to cause extrapyramidal side effects (EPS) or require the addition of adjunctive anticholinergic to treat EPS, modest cognitive advantages of these agents could be expected (26). Recent studies suggest that atypical antipsychotics do have a greater beneficial effect on cognitive function in schizophrenic patients (27-29).

\section{EPS and Depression}

It is not surprising that significant EPS may be correlated with dysphoria. Neuroleptic-induced akinesia and depression show a substantial phenomenological overlap (akinetic depression). In turn, depressive symptoms in psychotic illness have been related to substance abuse, suicidality, medication noncompliance, and greater morbidity (30-33). Atypical antipsychotics, possibly related to their lower propensity to cause EPS, have generally been found to be more efficacious than conventional antipsychotics in ameliorating the depressive symptoms in schizophrenia $(18,19)$.

\section{EPS and Tardive Dyskinesia}

Tardive dyskinesia, a movement disorder characterized by choreoathetoid and stereotyped involuntary movements, generally appears after several years of antipsychotic treatment. Early expression of EPS significantly increases the likelihood of subsequently developing tardive dyskinesia (34-36). Tardive dyskinesia, in turn, adds to the stigma associated with the illness, is disfiguring, and may hasten the patient's decline in social function; it is also associated with increased mortality. Atypical antipsychotics are predicted to be less likely to cause tardive dyskinesia because of their lower propensity to cause EPS $(37,38)$.

\section{EPS and Sense of Well-Being}

Symptoms of drug-induced parkinsonism are extremely distressing to patients, even though many patients do not spontaneously complain about these symptoms. A majority of patients find the subjective symptoms of EPS to be more distressing than the outwardly obvious physical signs (10). Subjective symptoms of EPS include dullness and apathy, "a zombielike feeling," and inner restlessness. It should be noted that many of these symptoms resemble aspects of schizophrenic psychopathology and their appearance can easily lead to the misstep of increasing the dose of the offending agent, thereby compounding the problem (10). An antipsychotic with a low incidence of EPS (atypical vs. conventional antipsychotics) thus can substantially improve patient comfort and simplify patient management $(39,40)$.

\section{EPS and Outcome}

The occurrence of EPS in the course of antipsychotic treatment is associated with poor response and reduced efficacy (41). EPS adversely impact the already-compromised level of function and quality of life of individuals suffering from schizophrenic illness. They contribute to stigmatization of the patient and increase the burden on caregivers. Patients treated with atypical antipsychotics have generally been found to exhibit better long-term outcome than those treated with conventional antipsychotics (13).

\section{WHAT DO THE NEWER "ATYPICAL ANTIPSYCHOTICS” OFFER?}

The defining characteristic of atypical antipsychotics is at least equal efficacy with a significantly lower liability of EPS than conventional agents; consequently, their use would be predicted to yield several benefits that go beyond reduction in parkinsonian motor side effects. Many of these advantages have been confirmed in clinical studies, but the putative benefits of atypicals on lowering EPS have different degrees of substantiation in the literature (Fig. 2). Therefore, to derive optimal benefits from the use of atypical antipsychotics, it is essential that they be used in a way that EPS not occur; if EPS occur in the course of treatment with an atypical antipsychotic, consideration should be given to a reduction in dose or change to another agent. Adequate control of psychotic symptoms with avoidance of EPS without 


\section{The EPS Advantage of Atypical Antipsychotics}

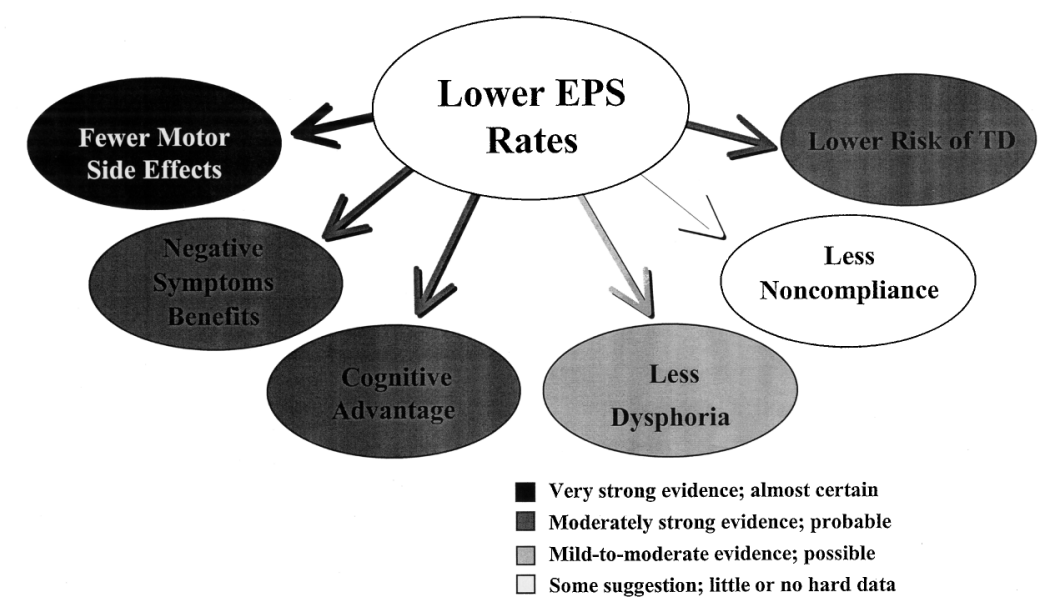

Fig. 2. The strength of the evidence varies for the putative benefits of atypical antipsychotics with respect to EPS.

adjunctive antiparkinsonian medication should be the objective.

Although the newer generation of antipsychotics are all associated with a lower liability of EPS when contrasted to the older generation of conventional antipsychotics (thereby providing the several benefits listed above to patients), there are clear differ- ences between them in this regard. This difference between different atypical antipsychotics with regard to the ease and consistency with which they provide this EPS advantage is reflected in the degree of separation between their respective antipsychotic and EPS dose-response curves (Fig. 3) (19, 37, 42). These different degrees of separation are of particular

\section{Dose-Response Curve: Antipsychotic Effects vs EPS}

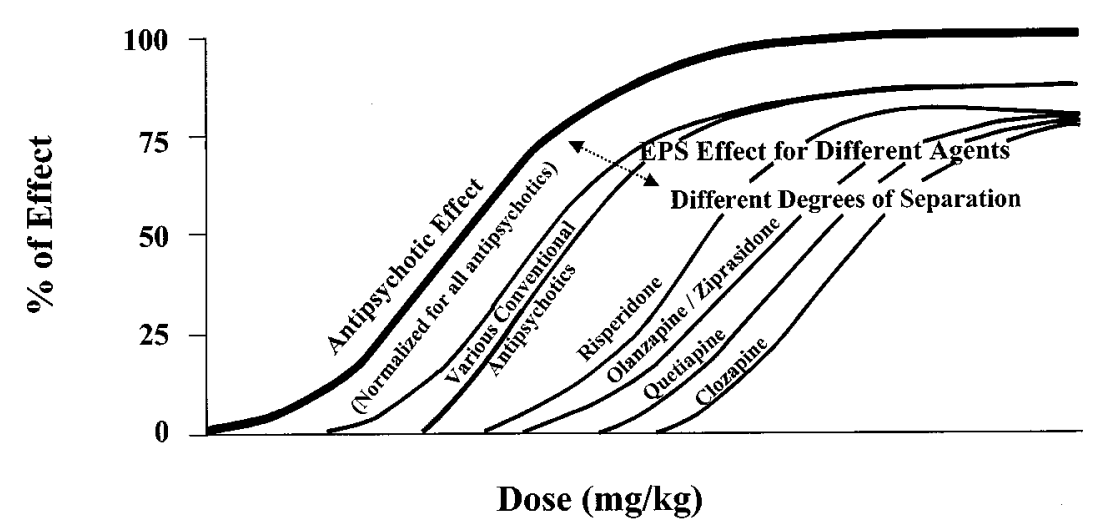

Fig. 3. A broader degree of separation is seen for all atypical antipsychotics in comparison to conventional antipsychotics. Among atypical antipsychotics, the different degrees of separation are likely to be reflected in their relative propensity to cause EPS with increasing doses (11). 
relevance in vulnerable patient populations and as the dosage of the "atypical" antipsychotic agent is increased. Whereas clozapine and quetiapine are not associated with any dose-dependent increase in risk of EPS across their entire dose range (5), olanzapine and ziprasidone can be associated with EPS (particularly akathisia) at their higher doses $(4,43)$, and risperidone is associated with a clear dose-dependent increase in risk of EPS (3). Regardless, when one uses any of the newer generation of "atypical" antipsychotics, it is crucial to recognize that the principal factor contributing to their multiple advantages over the older conventional agents is their lower liability of EPS. Consequently, when one uses these agents, it is essential to obtain a satisfactory antipsychotic effect without EPS and without using an anticholinergic antiparkinsonian agent; this "essence of atypicality" is the key to the multiple benefits associated with the use of the newer generation of antipsychotics.

\section{CONCLUSIONS}

The "costs" of EPS are not limited to parkinsonian motor manifestations, but extend to increased negative symptoms and cognitive impairment, more dysphoria, higher likelihood of noncompliance, and greater risk of developing tardive dyskinesia (37). The importance of EPS in the context of treatment of schizophrenic illness tends to be underestimated.
Expression of EPS significantly increases the likelihood of subsequent tardive dyskinesia; tardive dyskinesia, in turn, is associated with increased morbidity and mortality. EPS contribute to secondary negative symptoms, increasing the severity of this symptom dimension and attendant dysfunction. EPS are associated with cognitive dysfunction, attributable directly to unattenuated mesocortical dopamine blockade of the antipsychotic or to the adjunctive use of other anticholinergic agents to treat EPS. It is not surprising that significant EPS may be correlated with dysphoria. The "costs" of EPS are thus not limited to parkinsonian motor manifestations, but extend to increased negative and cognitive symptoms, more dysphoria, higher likelihood of noncompliance, and greater risk of tardive dyskinesia. These implications of various EPS are depicted in Fig. 4.

The new atypical antipsychotic medications represent a major step forward in the treatment of schizophrenia and other psychotic disorders. These agents are pharmacologically distinct from their neuroleptic predecessors. The primary advantage of the new agents is their superior side effect profiles, particularly with regard to EPS. The implications of EPS reduction touch virtually every domain of pathology in schizophrenia, including short- and long-term movement disorders, negative symptoms, noncompliance, relapse rate, cognitive dysfunction, and dysphoria. This EPS advantage of atypical antipsychotics is likely to lead to improved patient compliance and a

\section{Consequences of EPS}

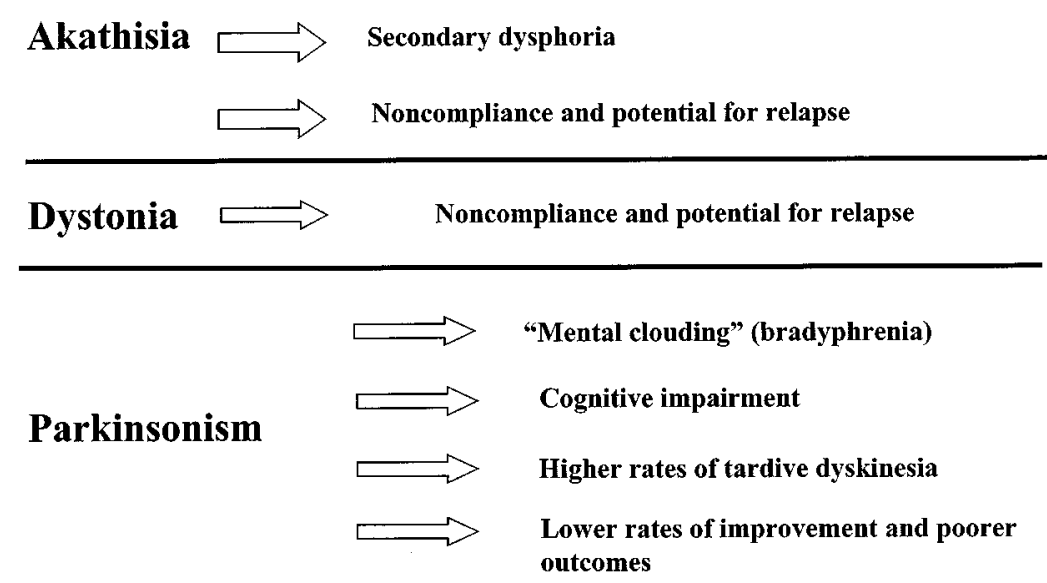

Fig. 4. The "costs" of EPS extend well beyond parkinsonian motor manifestations. 
superior long-term outcome in patients treated with these medications.

\section{ACKNOWLEDGMENT}

\section{Partial funding from AstraZeneca.}

\section{REFERENCES}

1. Tandon R: Antipsychotic agents. In: Klein DF, Rowland LP, eds. Current Psychotherapeutic Drugs. New York: Brunner/Mazel; 1998:120-154

2. Kane JM, Honigfeld G, Singer J, Meltzer H: Clozapine for the treatment-resistant schizophrenic: A double-blind comparison with chlorpromazine. Arch Gen Psychiatry 1988; 45:789796

3. Marder SR, Meibach RC: Risperidone in the treatment of schizophrenia. Am J Psychiatry 1994; 151:825-835

4. Beasley CM, Jr, Hamilton SH, Crawford AM, Tollefson G: Olanzapine versus haloperidol: Acute phase results of the international double-blind olanzapine trial. Eur Neuropsychopharmacol 1997; 7:125-137

5. Arvanitis LA, Miller BG: Multiple fixed doses of "Seroquel" (quetiapine) in patients with acute exacerbation of schizophrenia: A comparison with haloperidol and placebo. The Seroquel Trial 13 Study Group. Biol Psychiatry 1997; 42:233-246

6. Daniel DG, Zimbroff DL, Potkin SG, Reeves KR, Harrigan EP, Lakshminarayanan M: Ziprasidone $80 \mathrm{mg} /$ day and $160 \mathrm{mg} /$ day in the acute exacerbation of schizophrenia and schizoaffective disorder: A 6-week placebo-controlled trial. Ziprasidone Study Group. Neuropsychopharmacology 1999; 20:491-505

7. Casey DE: Motor and mental aspects of EPS. Int Clin Psychopharmacol 1995; 10:105-114

8. Van Putten T: The many faces of akathisia. Compr Psychiatry 1975; 16:43-47

9. Drake RE, Ehrlich J: Suicide attempts associated with akathisia. Am J Psychiatry 1985; 142:499-501

10. Van Putten T, May PR, Marder SR: Response to antipsychotic medication: The doctor's and the consumer's view. Am J Psychiatry 1984; $141: 16-19$

11. Hummer M, Fleischhacker WW: Compliance and outcome in patients treated with antipsychotics: The impact of extrapyramidal syndromes. CNS Drugs 1996; 5:13-20

12. Gilbert PL, Harris MJ, McAdams LA, Jeste DV: Neuroleptic withdrawal in schizophrenic patients. A review of the literature. Arch Gen Psychiatry 1995; 52:173-188

13. DeQuardo JR, Tandon R: Do atypical antipsychotic medications favorably alter the long-term course of schizophrenia? J Psychiatr Res 1998; 32:229-242

14. Miller DD, Tandon R: The biology and pathophysiology of negative symptoms. In: Keefe RSE, McEvoy JP, eds. Negative Symptom and Cognitive Deficit Treatment Response in Schizophrenia. Washington DC: American Psychiatric Press; 2001:163-186

15. Tandon R, Jibson MD, Taylor SF, DeQuardo JR: Conceptual models of the relationship between positive and negative symptoms. In: Shriqui CL, Nasrallah HA, eds. Contemporary Issues in the Treatment of Schizophrenia. Washington, DC: American Psychiatric Press; 1995:109-124

16. Tandon R, Goldman RS, DeQuardo JR, Perez M, Goodson $\mathrm{J}$, Jibson MD: Covariance of positive and negative symptoms during clozapine treatment in schizophrenia. J Psychiatr Res 1993; 27:341-347
17. Moller HJ, Muller H, Borison RL, Schooler NR, Chouinard G: A path-analytical approach to differentiate between direct and indirect drug effects on negative symptoms in schizophrenic patients. A re-evaluation of the North American risperidone study. Eur Arch Psychiatry Clin Neurosci 1995; 245:45-49

18. Tollefson GD, Sanger TM, Lu Y, Thieme ME: Depressive signs and symptoms in schizophrenia: A prospective blinded trial of olanzapine and haloperidol. Arch Gen Psychiatry 1998; $55: 250-258$

19. Tandon R, Milner K, Jibson MD: Antipsychotics from theory to practice: Integrating clinical and basic data. J Clin Psychiatry 1999; 60(Suppl 8):21-28

20. Bilder RM: Neurocognitive impairment in schizophrenia and how it affects treatment options. Can J Psychiatry 1997; 42:255264

21. Tandon R: Cholinergic aspects of schizophrenia. Br J Psychiatry 1999; 173(Suppl 37):7-11

22. Medalia A, Gold J, Merriam A: The effects of neuroleptics on neuropsychological test results of schizophrenics. Arch Clin Neuropsychol 1988; 3:249-271

23. Spohn HE, Strauss ME: Relation of neuroleptic and anticholinergic medication to cognitive functions in schizophrenia. J Abnorm Psychol 1989; 98:367-380

24. Tune LE, Strauss ME, Lew MF, Breitlinger E, Coyle JT: Serum levels of anticholinergic drugs and impaired recent memory in chronic schizophrenic patients. Am J Psychiatry 1982; 139:1460-1462

25. Strauss ME, Reynolds KS, Jayaram G, Tune LE: Effects of anticholinergic medication on memory in schizophrenia. Schizophr Res 1990; 3:127-129

26. Harvey PD, Keefe RSE: Cognitive impairment in schizophrenia and implications of atypical neuroleptic treatment. CNS Spectrums 1997; 2:41-55

27. Lee MA, Thompson PA, Meltzer HY: Effects of clozapine on cognitive function in schizophrenia. J Clin Psychiatry 1994; 55:82-87

28. Meltzer HY, McGurk SR: The effects of clozapine, risperidone, and olanzapine on cognitive function in schizophrenia. Schizophr Bull 1999; 25:23-255

29. Harvey PD, Keefe RSE: Studies of cognitive change in patients with schizophrenia following novel antipsychotic treatment. Am J Psychiatry 1999; 158:176-184

30. Tapp A, Kilzieh N, Wood AE, Raskind M, Tandon R: Depression in patients with schizophrenia during an acute psychotic episode. Compr Psychiatry 2001; 42:314-318

31. Siris SG: Depression in schizophrenia. Perspective in the era of "atypical" antipsychotic agents. Am J Psychiatry 2000; 157:1379-1389

32. Kamali M, Kelly L, Gervin M, et al.: The prevalence of comorbid substance misuse and its influence on suicidal ideation among in-patients with schizophrenia. Acta Psychiatr Scand 2000; 101:452-456

33. Atbasoglu EC, Schultz SK, Andreasen NC: The relationship of akathisia with suicidality and depersonalization among patients with schizophrenia. J Neuropsychiatry Clin Neurosci 2001; 13:336-341

34. Kane JM, Woerner M, Lieberman J: Tardive dyskinesia: Prevalence, incidence, and risk factors. J Clin Psychopharmacol 1988; 8(Suppl 4):52S-56S

35. Andrew HG: Clinical relationship of extrapyramidal symptoms and tardive dyskinesia. Can J Psychiatry 1994; 39(Suppl 2):S76-S80

36. Chatterjee A, Chakos M, Koreen A, Geisler G, Sheitmon B, Woerner M, Kane JM, Alvir J, Lieberman JA: Prevalence and clinical correlates of extrapyramidal signs and spontaneous dyskinesia in never-medicated schizophrenic patients. Am J Psychiatry 1995; 152:1724-1729

37. Jibson MD, Tandon R: New atypical antipsychotic medications. J Psychiatr Res 1998; 32:215-228 
38. Casey DE: Will the new antipsychotics bring hope of reducing the risk of developing extrapyramidal syndromes and tardive dyskinesia? Int Clin Psychopharmacol 1997; 12(Suppl 1):19_ 27

39. Naber D, Walther A, Kirshere T: Subjective events of neuroleptics predict compliance. In: Gaebel W, Awad AG, eds. Prediction of Neuroleptic Treatment Outcome in Schizophrenia. Vienna: Springer; 1999:111-122

40. Voruganti L, Cortese L, Oyewumi L, Awad G: Comparative evaluation of conventional and novel antipsychotic drugs with reference to their subjective tolerability, side-effect profiles, and impact on quality of life. Schizophr Res 2000; 43:135-145

41. Kinon BJ, Kane JM, Chakos M, Munne R: Possible predictors of neuroleptic-resistant schizophrenic relapse: Influence of negative symptoms and acute extrapyramidal side effects. Psychopharmacol Bull 1993; 29:365-369

42. Goldstein JM: The new generation of antipsychotics: How atypical are they? Int Clin Neuropharmacol 2000; 3:339-349

43. Jibson MD, Tandon R: Treatment of schizophrenia. Psychiatr Clin N Am, Ann Drug Ther 2000; 7:83-113 